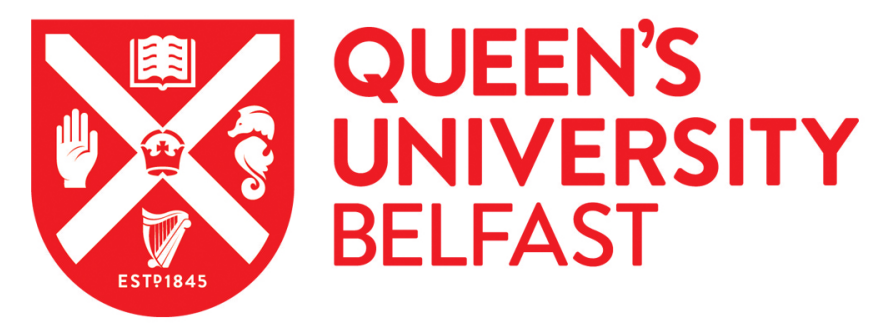

\title{
Proteomic Analysis of Recurrent Joint Inflammation in Juvenile Idiopathic Arthritis
}

Gibson, D., Blelock, S., Brockbank, S., Curry, J., Healy, A., McAllister, C., \& Rooney, M. (2006). Proteomic Analysis of Recurrent Joint Inflammation in Juvenile Idiopathic Arthritis. Journal of Proteome Research, 5(8), 1988-1995. https://doi.org/10.1021/pr060129t

Published in:

Journal of Proteome Research

Queen's University Belfast - Research Portal:

Link to publication record in Queen's University Belfast Research Portal

\section{General rights}

Copyright for the publications made accessible via the Queen's University Belfast Research Portal is retained by the author(s) and / or other copyright owners and it is a condition of accessing these publications that users recognise and abide by the legal requirements associated with these rights.

Take down policy

The Research Portal is Queen's institutional repository that provides access to Queen's research output. Every effort has been made to ensure that content in the Research Portal does not infringe any person's rights, or applicable UK laws. If you discover content in the Research Portal that you believe breaches copyright or violates any law, please contact openaccess@qub.ac.uk. 


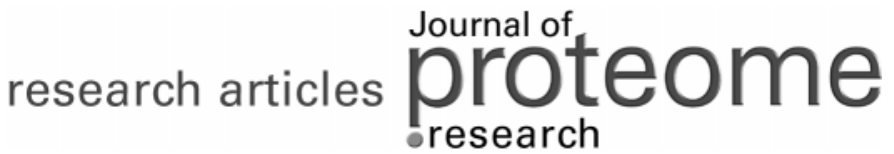

\section{Proteomic Analysis of Recurrent Joint Inflammation in Juvenile Idiopathic Arthritis}

\author{
David S. Gibson, ${ }^{*, \dagger}$ Sarah Blelock, ${ }^{\dagger}$ Simon Brockbank, ${ }^{\ddagger}$ Jim Curry, ${ }^{\ddagger}$ Adrienne Healy, ${ }^{\S}$ \\ Catherine McAllister, ${ }^{\dagger}$ and Madeleine E. Rooney ${ }^{\dagger}$
}

\begin{abstract}
Queen's University Belfast, Arthritis Research Group, Musculoskeletal Education and Research Unit, Musgrave Park Hospital, Belfast BT9 7JB, Northern Ireland, Queen's University Belfast, Ophthalmology and Vision Sciences, Institute of Clinical Science, Royal Victoria Hospital, Belfast BT9 7JB, Northern Ireland, and Queen's University Belfast, Centre for Peptide and Protein Engineering, School of Biology and Biochemistry,
\end{abstract} Medical Biology Centre, Belfast BT9 7JB, Northern Ireland

Received March 30, 2006

The synovial fluid proteome in juvenile idiopathic arthritis was investigated to isolate joint-specific biomarkers that are expressed in patients displaying recurrent joint inflammation. To identify the synovial specific proteome, matched synovial fluid and plasma samples were subjected to protein separation by 2-dimension electrophoresis (2DE). Forty-three protein spots, overexpressed in the joint, were identified. Synovial fluids from children with single-event knee joint inflammation were then compared with a group with recurrent knee disease. Nine synovial specific proteins were significantly differentially expressed in the recurrent group. Proteolytic fragments of collagen $\mathbf{X}$, fibrin $\beta$-chain, and T-cell receptor $\alpha$-region have been identified among this protein cluster. Putative biomarkers, overexpressed in the joint and differentially expressed in children with recurrent joint inflammation, have been identified. These proteins may play a significant role determining the pathological state within the chronically inflamed joint and influence disease progression in JIA. This is the first study of the synovial proteome in children.

Keywords: juvenile idiopathic arthritis • biomarker $\bullet$ inflammation $\bullet$ synovial fluid $\bullet$ plasma

\section{Introduction}

Juvenile idiopathic arthritis (JIA) comprises a group of chronic, childhood onset, autoimmune diseases with variable clinical presentations, outcomes, and therapeutic responses. JIA is one of the commonest chronic diseases of childhood, affecting one in every thousand children.

Previous studies over the past few decades have evaluated outcome, in terms of clinical remission, physical disability and radiographic damage. ${ }^{1,2} \mathrm{~A}$ high percentage of JIA patients may develop unremitting inflammatory disease $(40-60 \%)$, with a considerably higher risk of developing progressive joint destruction $(10 \%) .^{3}$

JIA is divided into a number of clinically distinct subgroups according to the ILAR criteria. ${ }^{4}$ These include oligoarthritis, extended oligoarthritis, poly-articular rheumatoid factor-positive $(\mathrm{RF}+\mathrm{ve})$, polyarticular RF-ve, enthesitis, psoriatic, and systemic disease. Joint inflammation is a feature common to all. Ravelli's review findings indicate that the long-term out-

* To whom correspondence should be addressed. Arthritis Research Group, Queen's University Belfast, Musculoskeletal Education and Research Unit, Musgrave Park Hospital, Stockmans Lane, Belfast. BT9 7JB. Northern Ireland. Tel: +44(0)2890902877. Fax: +44(0)289066 1112. E-mail: d.gibson@ qub.ac.uk.

${ }^{\dagger}$ Musgrave Park Hospital.

‡ Royal Victoria Hospital.

$\$$ Medical Biology Centre. come for JIA patients is best in persistent oligo-articular disease and worst in the RF+ve poly-articular group. The widely variable outcomes of JIA reflects the heterogeneity of inflammatory activity associated with a specific disease subtype. ${ }^{5,6}$ Although recent treatment strategies are more effective, reducing the frequency of severe disability, there remains a high proportion of patients who continue to present with persistent inflammatory disease into young adulthood. ${ }^{7}$ Moreover, it is known that joint damage may progress despite decreased inflammatory activity and erosions may develop in patients with few signs of inflammation by conventional laboratory and clinical assessments. ${ }^{5}$

Predicting the progression and consequence of JIA inflammatory pathology is therefore essential for optimal clinical management. The current prognostic and therapeutic rationale is focused on clinical evaluation and radiographic monitoring of inflamed synovial joints and subsequent administration of appropriate anti-rheumatic drugs.

We noted through clinical observation, that in some children, recurrent joint inflammation occurred despite intra-articular steroid treatment and irrespective of the disease subtype. Although JIA was previously thought of as a benign disease, a considerable number of JIA patients will continue to suffer persistent inflammatory disease with a significant proportion developing severe disabilities. ${ }^{8,9}$ We postulate that biomarkers

10.1021/pr060129t CCC: $\$ 33.50$ (C) 2006 American Chemical Society 
Table 1. Clinical and Demographic Characteristics of the Study Subjects ${ }^{a}$

\begin{tabular}{lcc} 
& $\mathbf{1 A}$ & \\
\hline & single event & recurrent \\
\hline no. & 3 & 3 \\
oligo/ poly & $1 / 2$ & $1 / 2$ \\
mean age (years) & $9.3 \pm 5.69$ & $7.3 \pm 4.04$ \\
male/female (n) & $1 / 2$ & $1 / 2$ \\
mean duration of JIA & $6.0 \pm 4.36$ & $7.1 \pm 6.47$ \\
& $\mathbf{1 B}$ &
\end{tabular}

\begin{tabular}{|c|c|c|c|c|c|c|}
\hline \multirow[b]{2}{*}{ inflammation group } & \multicolumn{3}{|c|}{ single event } & \multicolumn{3}{|c|}{ recurrent } \\
\hline & oligo & poly* & total & oligo & poly* & total \\
\hline no. & 6 & 7 & 13 & 7 & 6 & 13 \\
\hline age (years) & $9.8 \pm 4.8$ & $13.17 \pm 5.78$ & $11.5 \pm 5.37$ & $7.3 \pm 3.83$ & $7.83 \pm 5.71$ & $7.54 \pm \mathbf{4 . 4 6}$ \\
\hline male/female (n) & $0 / 6$ & $3 / 4$ & $3 / 10$ & $1 / 6$ & $3 / 3$ & $4 / 9$ \\
\hline duration of JIA (years) & $5.8 \pm 3.19$ & $8.17 \pm 3.97$ & $6.58 \pm 3.8$ & $1.71 \pm 2.03$ & $7.5 \pm 3.83$ & $2.58 \pm 4.12$ \\
\hline inflammation frequency (months) & & & & $10.3 \pm 8.12$ & $12.67 \pm 7.47$ & $11.5 \pm 7.54$ \\
\hline no. of swollen joints (n) & $3.5 \pm 0.71$ & $2.5 \pm 0.55$ & $2.5 \pm 0.88$ & $3 \pm 1.41$ & $3.67 \pm 1.63$ & $3.1 \pm 1.6$ \\
\hline serum CRP $(\mathrm{mg} / \mathrm{l})$ & $29.5 \pm 34.3$ & $36.1 \pm 50.4$ & $34.2 \pm 43.6$ & $8.7 \pm 8.4$ & $20.2 \pm 27.1$ & $15.6 \pm 21.6$ \\
\hline ESR $(\mathrm{mm} / \mathrm{hr})$ & $45.5 \pm 20.5$ & $28.6 \pm 28.9$ & $33.4 \pm 26.4$ & $12.2 \pm 9.9$ & $15.7 \pm 4.2$ & $14.1 \pm 7.2$ \\
\hline NSAID (yes/no) & $3 / 3$ & $5 / 2$ & $8 / 5$ & $4 / 3$ & $6 / 0$ & $10 / 1$ \\
\hline DMARD (yes/no) & $1 / 5$ & $2 / 5$ & $3 / 10$ & $0 / 6$ & $3 / 3$ & $3 / 9$ \\
\hline
\end{tabular}

${ }^{a}$ Values are the mean ( standard deviation or the number of subjects. $\sim=$ not determined; CRP $=$ C-reactive protein; ESR $=$ erythrocyte sedimentation rate; * rheumatoid factor negative.

may exist, which mediate persistence of inflammation across the disease subtypes. A search for mediators of inflammation persistence within a given joint might thus increase our understanding of childhood inflammatory joint disease.

Others have looked for prognostic markers within disease subgroups, for example some studies have attempted to identify early prognostic factors, such as rheumatoid factor. ${ }^{8,10}$

More recently biomarker discovery studies on adult arthritis have adopted a more rigorous and global analysis platform for protein expression patterns based on two-dimensional electrophoresis (2-DE) or liquid chromatography (LC) coupled with highly sensitive mass spectrometry (MS). ${ }^{11,12} 2$-DE is a highresolution method for unscrambling complex protein mixtures in two dimensions, according to their isoelectric point $(\mathrm{p} I)$ in the first dimension and size (molecular weight) in the second dimension. This large-scale characterization of the total protein compliment, or proteome, was adopted in our investigation to elucidate specific differences, in local pathology of the inflamed joint. Rather than looking for differences between disease subtypes we wished to look for protein markers which would occur in those patients with recurrent joint inflammation as opposed to those markers present in joints which responded to treatment.

We therefore wished to look at two groups of patients; those with a single episode of joint inflammation which settled following intra-articular steroid and those with recurrence of inflammation within that joint, despite treatment, during a defined time period. We believe this might identify markers of disease persistence common to all subtypes of JIA.

We believe it is essential to identify the synovial fluid proteome from those proteins produced systemically and secreted into plasma by a wide variety of non synovial cells, as it is within the joint that destruction occurs.

Although the systemic component of JIA may be important, this preliminary study has focused on elucidating those proteins which are exclusively expressed or at least over represented within the joint space.
We therefore wished to study the synovial proteome in JIA and attempt to identify a specific proteome which occurred in persistent disease.

\section{Materials and Methods}

Patients, Synovial and Plasma Samples. This paper describes three studies:

1. The Synovial Specific Proteome. In the first study, we wished to identify the synovial fluid specific proteome. Six patients (Table 1A) with matched plasma and synovial fluid samples were used ( 2 with oligo-articular and 4 with polyarticular arthritis). Having identified synovial fluid specific proteins (vide infra) i.e., those only expressed in synovial fluid we then used these data to compare the expression of these proteins between solitary and recurrent episodes of joint inflammation in our second study.

2. Synovial Expression Profile Associated with Inflammation Recurrence. Twenty-six patients with juvenile idiopathic arthritis (JIA) according to ILAR criteria entered this second study (Table 1B). ${ }^{4}$ There were 13 children with oligo-articular arthritis and 13 with RF-ve poly-articular arthritis. Children were monitored for a period of $3 \mathrm{y}$. During this period, all subsequent swelling of a single identified joint was recorded, with synovial fluid and plasma obtained at each treatment intervention.

All patients were examined by a consultant rheumatologist, (MR), who confirmed their diagnosis. For the purposes of this second study, only initial synovial fluids were studied. Children were divided into two groups, those with a solitary episode of knee synovitis which resolved with a single steroid injection and those with recurrent joint synovitis requiring multiple steroid injections.

Intra-articular steroid (Triamcinolone acetonide) injections of the knee were performed with ultrasound guidance, under general anesthetic, with the dose determined by the size of the joint. (Triamcinolone hexacetonide was not available during the time of this study). Clinical details recorded included 
subtype of JIA, age, sex, disease duration, local and general disease activity and where appropriate -time to local recurrence, ESR and CRP. Local inflammation was defined as both joint swelling and pain on physical examination.

3. Confirmation of Protein Identity and Change in Expression Over Time. In our third and final study, we followed the expression of a specific group of biomarkers in the synovial fluids of five individuals ( 2 with oligo-articular, 3 with polyarticular arthritis) with recurrent joint inflammation at the time of reaspiration. We hoped this would give us some insight into the changes in protein expression during the time course of the disease.

All synovial fluids (SF) were aspirated using an aseptic technique and plasma obtained at the same procedure. The SF and plasma samples were immediately centrifuged at 5000 $\times g$ for $15 \mathrm{~min}$ at $4^{\circ} \mathrm{C}$ to remove any particulate or cellular material, aliquoted and stored at $-80^{\circ} \mathrm{C}$ until analyzed. Medical Ethics Committee approval was obtained for this study at Green Park Healthcare Trust and patient assent and parent informed consent given.

Sample Treatment. Proteins within patient fluids were extracted and stabilized for $1 \mathrm{~h}$ at $4{ }^{\circ} \mathrm{C}$ by addition of M-PER protein extraction reagent (Pierce Biotechnology Inc., Rockford, USA) and a protease inhibitor cocktail (Roche Diagnostics $\mathrm{GmbH}$, Mannheim, Germany). Samples were subsequently dialyzed overnight at $4{ }^{\circ} \mathrm{C}$ in distilled water to remove salts, with 3.5 KDa cutoff membrane Slide-A-Lyzer cassettes (Pierce Biotechnology Inc., Rockford, USA). Each purified patient fluid was snap frozen in liquid nitrogen and lyophilized overnight under vacuum on a Christ freeze-dryer (Martin Christ GmbH, Osterode am Harz, Germany). Matched synovial fluid and plasma samples were rehydrated in sample rehydration buffer (8 M Urea, 2\% CHAPS and $0.002 \%$ bromophenol blue) (Invitrogen Ltd., Paisley, UK), with gentle agitation to prevent foaming. Protein concentrations were measured using the PlusOne 2-D Quant kit according to manufacturer's guidelines (Amersham Biosciences UK Ltd., Bucks, UK).

2-Dimensional Gel Electrophoreisis (2-DE). 2-DE was performed at room temperature with a ZOOM IPGRunner System, an XCell SureLock Mini-Cell and associated power supply, strips, gels, and reagents according to the manufacturer's guidelines (Invitrogen Ltd., Paisley, UK). A 200- $\mu$ g portion of soluble protein extract was made up to a total volume of 160 $\mu \mathrm{L}$ in sample rehydration buffer, containing final concentrations of $20 \mathrm{mM}$ dithiotreitol and $0.5 \%(\mathrm{v} / \mathrm{v}) \mathrm{pH} 4-7$ carrier ampholytes (Invitrogen Ltd., Paisley, UK). Each sample was applied to a linear $\mathrm{pH} 4-7$ immobilized $\mathrm{pH}$ gradient (IPG) strip and rehydrated overnight. Pilot runs with $\mathrm{pH} \mathrm{3-10} \mathrm{carrier}$ ampholytes and IPG strips revealed most of the proteins focused within the $\mathrm{pH} 4-7$ range. The first dimension separation of proteins by isoelectric focusing (IEF) was performed in triplicate $(n=3)$ at $500 \mathrm{~V}$ for $4 \mathrm{~h}(1 \mathrm{~mA} / 0.5 \mathrm{~W}$ limit per strip) with a final $2000 \mathrm{~V}$ step for $45 \mathrm{~min}$ to obtain high quality resolution. After IEF, the strips were equilibrated in NuPAGE LDS Sample Buffer by two 15 min steps with gentle shaking, first with $1.5 \%$ dithiotreitol $(\mathrm{w} / \mathrm{v})$ added as a reducing agent and second with $125 \mathrm{mM}$ iodoacetamide included to reduce protein streaking by alkylation. Post-equilibration, IPG strips were laid into single well $4-12 \%$ Bis-Tris gels and sealed in with $0.5 \%$ agarose $(\mathrm{w} / \mathrm{v})$ in running buffer. $10 \mu \mathrm{L}$ of SeeBlue Plus2 protein molecular weight ladder was used per gel. The second dimension (molecular weight) separation was achieved with denaturing polyacrylamide gel electrophoresis (SDS-PAGE) run at $200 \mathrm{~V}$ for $50 \mathrm{~min}$. Focused protein spots were fixed ingel with $40 \%$ methanol/ $7 \%$ acetic acid $(\mathrm{v} / \mathrm{v})$ in distilled water for $15 \mathrm{~min}$. Gels were washed thoroughly in distilled water and stained overnight with GelCode Blue colloidal Coomassie stain reagent (Pierce Biotechnology Inc., Rockford, USA).

Image Analysis. Gels were scanned as 16 bit gray scale Tif image files with a GS-800 Calibrated Densitometer (Bio-Rad Laboratories Inc., Hercules, USA) and the protein spot intensities were quantified using Phoretics 2D Expression software package version 2005 build 1742.8 (Nonlinear Dynamics Ltd., Newcastle upon Tyne, UK). Spots were detected, matched and volumes normalized within replicate $(n=3)$ gel sets to create 'master' gels for a series of corresponding samples. In study 1 individual plasma and matched synovial fluid samples from six patients were studied in triplicate. Using the analysis software, triplicate gel images were combined to create six SF and six plasma 'master' gels. Subsequent qualitative subtraction of plasma from matched synovial fluid 'master' gels revealed a population of proteins uniquely expressed in the joint in all six patients.

In study 2, we recruited 26 patients; 13 with a single episode of knee joint inflammation and 13 in whom inflammation in that knee joint was recurrent. Only synovial fluid samples obtained at the first episode of joint inflammation were studied. Synovial fluids from the two groups were pooled. Master gels were created, this time from five replicate gels for each group. Quantitative differential spot analysis was performed on 'master' gels from the two groups. The threshold for accepting a meaningful variation was set at a 2 -fold change and statistical analysis to find significant differences between compared spots was performed using the Student's $t$-test $(p<0.05)$.

Protein Spot Extraction and Identification. Those proteins from studies 1 and 2 that were expressed exclusively within synovial fluid were identified by nanoelectrospray ionization mass-spectrometry (nESI-MS). Protein spots were excised manually using sterilized $200 \mu \mathrm{L}$ pipet tips cut to suitable bore width. Matched spots within replicate gels were pooled, washed twice in distilled water and destained with $50 \mathrm{mM}$ ammonium bicarbonate $\mathrm{pH} 7.8$ in $40 \%$ ethanol (v/v). The gel pieces were finely chopped, dehydrated with acetonitrile and dried in HT-4 Series II centrifugal evaporator for $30 \mathrm{~min}$ (GeneVac Ltd., Ipswich, UK). Sequencing grade, modified trypsin (Promega Corporation, Madison, USA) diluted $(75 \mathrm{ng} / \mu \mathrm{L})$ in $25 \mathrm{mM}$ ammonium bicarbonate was added to the gel pieces followed by overnight digestion at $37{ }^{\circ} \mathrm{C}$. Digested peptides were extracted in $5 \%$ trifluoroacetic acid, $50 \%$ acetonitrile in ultrapure water with sonication for $6 \mathrm{~min}$. After a gel pellet was formed by brief centrifugation, the supernatant was desalted using a C18 ZipTip (Pierce Biotechnology Inc., Rockford, USA) and dehydrated in SC 210A Speed Vac vacuum evaporator (Savant Instruments Inc., Hicksville, USA). Desalted peptide digests were subjected to nanoelectrospray-ionization (nESIMS/MS) with a LCQ Deca ion trap-mass spectrometer (ThermoFinnegan, San Jose, USA), operated with dynamic exclusion via LCQ Tune software. MS/MS data was collected by Xcalibur and MS/MS ion search was performed by Mascot search engine (Matrix Science Inc., Boston, USA), using the database NCBInr. Mascot used the Mowse scoring algorithm. ${ }^{13}$ This indicates that the identity is significant if it would be expected to occur at random with a frequency of less than $5 \%$.

2-DE Western Immunoblot. Western immunoblot was used in order to confirm the mass spectrometry findings (of study 2) and further analyze protein expression over time (study 3). 
The focused protein spots from selected 2-DE gels were transferred to $0.45 \mu \mathrm{m}$ Biotrace NT nitrocellulose membrane (Pall Corproration, Portsmouth, UK) with an XCell II Blot Module, associated buffers and power supply, according to the manufacturer's guidelines (Invitrogen Ltd., Paisley, UK). Nonspecific binding was blocked overnight at $4{ }^{\circ} \mathrm{C}$ using $5 \%$ nonfat milk in PBS with $0.1 \%$ Tween 20 (PBST) (Sigma-Aldrich Company Ltd., Gillingham, UK). Anti-human monoclonal primary antibodies to Collagen X (COL-10; Sigma-Aldrich Ltd., Gillingham, UK) and T-cell $\alpha \beta$ receptor (T10B9; Biolegend, San Diego, USA) were incubated with blotted membranes at a dilution of 1:500 in PBST, for $1 \mathrm{~h}$ at RT. After the membranes were washed 3 times (5 $\mathrm{min}$ each) with PBST, they were incubated in horseradish peroxidase conjugated secondary antibodies diluted to 1:2500-1:5000 in PBST (Sigma-Aldrich Company Ltd., Gillingham, UK), for $1 \mathrm{~h}$ at room temperature. After a further 6 washes, bands were visualized using Supersignal West Pico chemiluminescent substrate (Pierce Biotechnology Inc., Rockford, U.S.A.), imaged with a Autochemi CCD camera and analyzed with Labworks software version 4.0.0.8 (UVP Ltd., Cambridge, UK).

\section{Results}

1. The Synovial Specific Proteome. The simultaneous analysis of individual paired plasma and synovial fluids from six patients (Table 1A) was used initially to isolate joint-specific protein expression profiles, without introducing bias from interindividual differences. Pilot 2-DE gels revealed that the majority of proteins from the sampled fluids migrated to within the $\mathrm{pH}$ 4-7 range (results not shown). We determined intra- and intersample variability in protein concentration by analyzing changes in spot intensity over three replicate 2-DE gels, per sample. Visual inspection of replicate sets indicated that spot intensity, coordinate $(\mathrm{p} I / \mathrm{MWt})$ and intensities were similar between gels run from the same sample, but significant differences were noted between patient's and more importantly between plasma and synovial fluid.

Approximately 480 spots per gel in synovial fluid and 570 spots per gel in plasma were automatically detected by Phoretix software analysis of scanned gel images. Protein spots were uniquely numbered by synchronization to those in a reference gel. Intensity differences in spots matched between synovial and plasma master gels were also quantified.

A series of 43 synovial fluid proteins were isolated that remained unmatched or were expressed at a higher level than could be detected within the plasma. Statistical analysis of intra-sample variance revealed 18 spots within this subgroup were consistently expressed in all patients studied.

These putative synovial specific biomarker proteins are identified in Figure 1A (spot nos. 44-480). Ten control spots expressed with regular frequency across corresponding plasma and synovial fluid samples are highlighted in Figure 1B and were used for comparative purposes. Within this batch of control protein spots, some proteins were found to be equally represented between plasma and synovial fluid, while others tended to predominate in plasma.

2. Synovial Expression Profile-Associated with Inflammation Recurrence. The demographic and clinical characteristics of the patient cohort are summarized in Table 1B, with values representing the mean \pm standard deviation. The 'single event' group by definition had only one episode of knee joint inflammation which settled following treatment. The recurrent

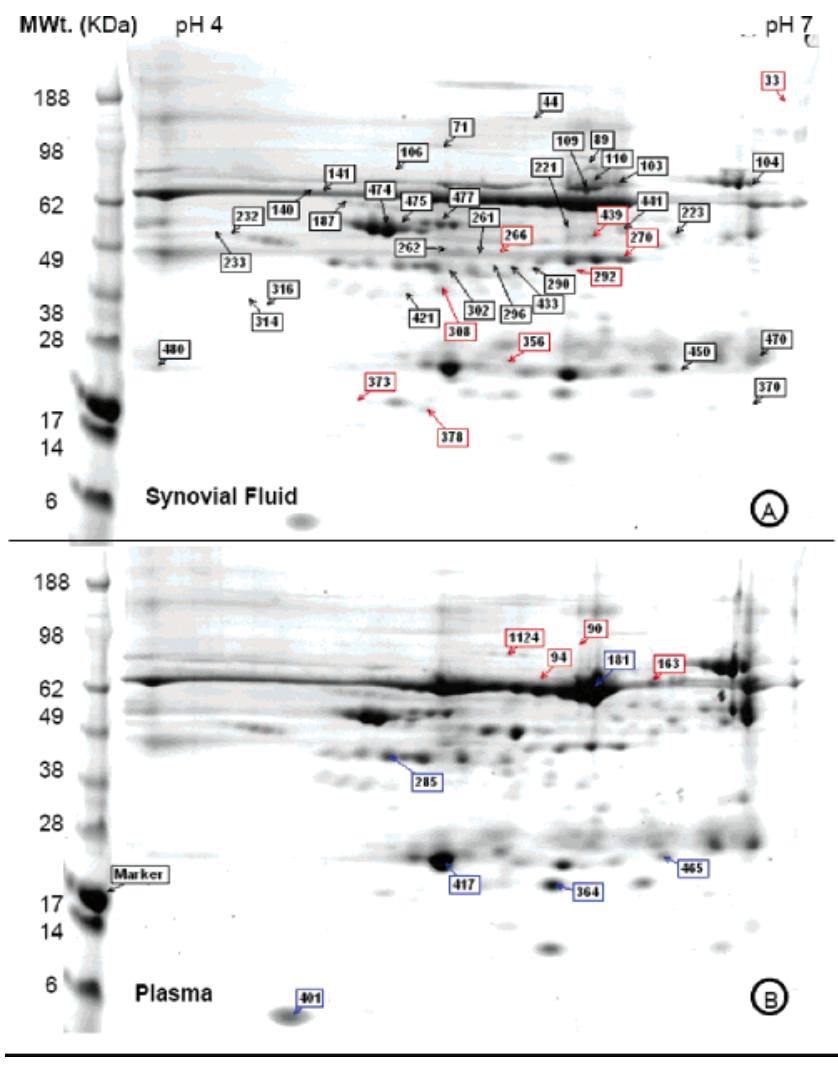

Figure 1. Isolation of synovial specific proteome. 2-DE reveals $\sim 480$ spots per gel within the $\mathrm{pH} \mathrm{4-7}$ range for synovial fluid and $\sim 570$ for plasma. A subpopulation of spots unique to (red labels), or overexpressed (black) were detected in synovial fluid (Figure 1A). Proteins present either exclusively in plasma (red), or present both in plasma and synovial fluid (blue), (Figure 1B). Intensity was determined by software analysis.

group had between two and four episodes of knee inflammation during the study period.

The recurrent group displayed a trend toward a lower mean age of $7.54 \pm 4.46$ years at the initial inflammatory episode vs $11.5 \pm 5.37$ years for the patients with a single inflammatory episode. The mean time period between bouts of joint inflammation within the recurrent group is $11.5 \pm 7.54$ months.

In both groups the female-to-male ratio was 2:1. The traditional markers of acute inflammation, C-reactive protein (CRP) and erythrocyte sedimentation rate (ESR), were higher in the single event group than in the recurrent. This finding may reflect the novel categorization of the patients in this study or indeed an outlier, as the standard deviation was wide.

Synovial fluid samples from patients with recurrent joint inflammation ( $n=13$ ) were compared by 2 -DE to those with nonrecurrent inflammation $(n=13)$, shown in Figure 2 . Proteins that were differentially expressed between the two groups were considered for selection as biomarker candidates. Each group master gel was pseudo-colored as part of the Phoretix comparative analysis, to isolate which proteins were significantly over or under expressed in the recurrent patient group. Green designated the single event inflammation group, whereas purple was used for the recurrent group. This allows a purely qualitative measure of the number, intensity and location of proteins which predominate in either patient group. Three particular areas (Figure 2A-C) within each master gel were investigated in greater detail. Possible biomarker candidates were selected if expressed at $\geq 2$-fold intensity in recurrent 

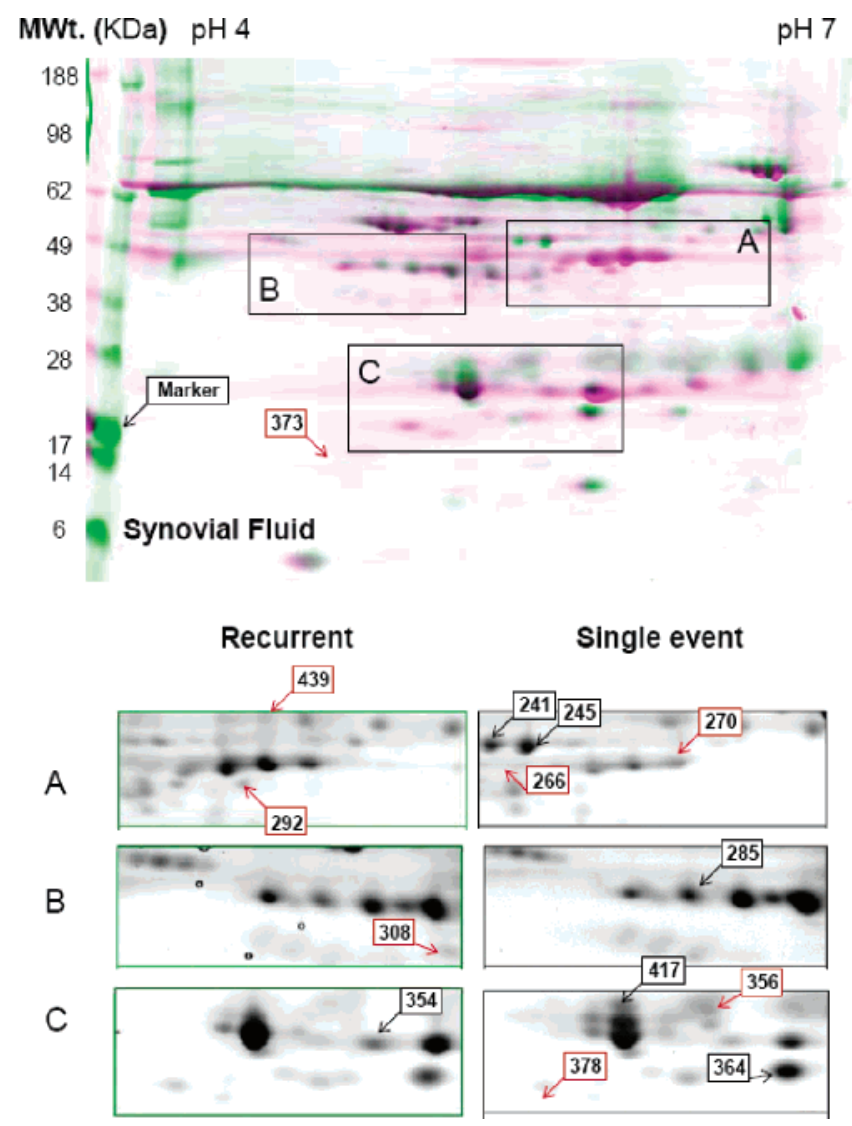

Figure 2. Synovial expression profiles correlated with chronic inflammation. Master SF 2-DE gels (top) from two subgroups of JIA patients ( $n=13$ each) that display either single-event or recurrent joint inflammation. Green pseudo-color designates the single event sample group and purple represents the recurrent inflammation group. Spots within areas A, B, and C indicated by arrows were picked and analyzed by ESI-MS/MS. Synovial specific spots are indicated by red labels.

inflammation samples compared to single event samples (or vice versa). Since master gels were composed of triplicate runs of pooled patient samples, each protein marker selection was subjected to ANOVA statistical test $(p<0.05)$ to assess intergel variation in spot intensity. The proteins with fold differences in expression which reached statistical significance and their identities, ascertained by nESI-MS/MS, are displayed in Table 2.

Nine of the 43 protein spots, specific to the synovial joint, were overexpressed in the recurrent group. Six of these biomarker candidates, with sufficient yields from pepsin digests, were identified by mass spectrometry with a high degree of confidence $(p<0.05)$ in sequence homology relative to the NCBInr database.

Spot nos. 266, 270, and 378 were identified as fibrin, fibrinogen, and haptoglobin-1 respectively, though the difference in expression between patient groups was below the 2 -fold threshold for these proteins.

Spot nos. 292, 373, and 439 were identified as haptoglobin2, T-cell receptor type $C$ and Collagen $X$ with $3.10,3.61$, and 2.03-fold increased expression respectively in the recurrent patient group.

3. Confirmation of Protein Identity and Change in Expression Over Time. T-cell receptor $\alpha \beta$ and collagen X expression profiles were selected for further investigation. The detection

\section{A Collagen $x$}

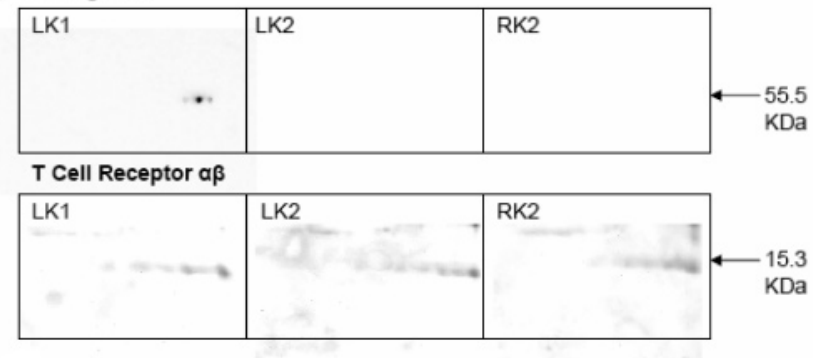

B
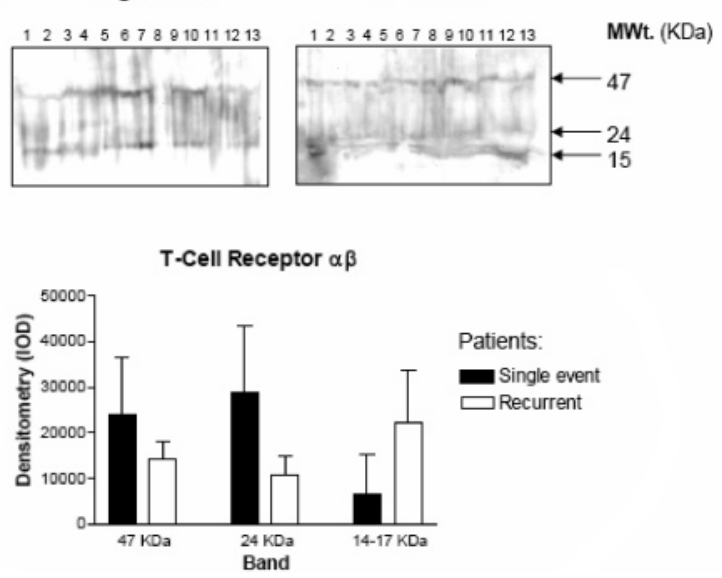

Figure 3. Confirmation of proteomic biomarkers. Enlarged areas from 2-DE-Western immunoblots for collagen $X$ and T-cell receptor peptides (Figure $3 \mathrm{~A}$ ) The immunoblots represent synovial fluid from a single individual displaying recurrent episodes of inflammation of the left knee (LK), with subsequent inflammation of the right knee (RK). Conventional 1D Western immunoblot for T-cell receptor peptides of individual's synovial fluids (one per lane) within the single and recurrent study groups (Figure 3B).

of these proteins within the synovial fluid-specific cluster, from patients with recurrent joint inflammation, identified them as possible inflammatory biomarkers. The expression of T-cell receptor $\alpha \beta$ and collagen $\mathrm{X}$ was confirmed by immunoblot.

We subsequently investigated whether these two candidate proteins were consistently expressed in synovial fluid samples over time. Five individual patients with recurrent joint inflammation were selected. We quantified the presence of these proteins in their individual sequential SF samples over time. The results for one individual are shown in Figure 3A. Here Collagen $\mathrm{X}$ expression was limited to the initial inflammatory episode, with a distinctive series of three $\sim 55 \mathrm{KDa}$ spots, the center spot being the most abundant. Collagen $\mathrm{X}$ expression was detectable in 3 of the 5 individuals tested with recurrent inflammation. The T-cell receptor $\alpha \beta$ (TCR) fragment expression, on the other hand, was detected consistently in all recurrently inflamed joints as demonstrated in the patient shown in Figure 3A. Furthermore, in that patient, TCR fragments were also present in the SF from the contralateral knee (RK2) which subsequently became inflamed. The TCR fragments appear as a series of faint spots with molecular weights ranging from 15 to $50 \mathrm{KDa}$, with the most abundant being 15 KDa.

We used conventional single dimension electrophoresis combined with Western blotting in order to establish whether 
Table 2. Identification and Quantification of Inflammation-Associated Proteins ${ }^{a}$

\begin{tabular}{|c|c|c|c|c|c|c|c|c|c|}
\hline $\begin{array}{l}\text { spot } \\
\text { ID }\end{array}$ & protein ID & $\begin{array}{l}\text { mowse } \\
\text { score }\end{array}$ & $\begin{array}{l}\text { no. of peptide } \\
\text { queries matched }\end{array}$ & accession & $\mathrm{pI}$ & $\begin{array}{l}\text { mass } \\
(\mathrm{KDa})\end{array}$ & $\begin{array}{c}\text { unique to } \\
\text { synovial fluid }\end{array}$ & $\begin{array}{l}\text { fold difference in } \\
\text { recurrent patients }\end{array}$ & $\begin{array}{l}\text { spot in } \\
\text { figure }\end{array}$ \\
\hline M & myoglobin marker control & & & & & 17 & $\mathrm{n} / \mathrm{a}$ & $\mathrm{n} / \mathrm{a}$ & $1 \mathrm{~B}, 2$ \\
\hline 33 & not identified & & & & 6.73 & 114 & $\mathrm{X}$ & 6.25 & $1 \mathrm{~A}$ \\
\hline 94 & serum albumin precursor & 121 & 5 & AAF01333 & 5.77 & 75 & & -1.97 & $1 \mathrm{~B}$ \\
\hline 163 & serum albumin chain A & 121 & 5 & CAA23754 & 6.36 & 63.5 & & -1.48 & 1B \\
\hline 181 & serum Abumin & 308 & 14 & AAF01333 & 6.08 & 63 & & -0.39 & $1 \mathrm{~B}$ \\
\hline 241 & not identified & & & & 5.64 & 51.5 & & -3.21 & $2 \mathrm{~A}$ \\
\hline 245 & not identified & & & & 5.76 & 50.2 & & -4.63 & $2 \mathrm{~A}$ \\
\hline 266 & fibrin beta chain & 77 & 2 & 0401173A & 5.69 & 47.5 & $\mathrm{X}$ & -1.1 & $1 \mathrm{~A}, 2 \mathrm{~A}$ \\
\hline 270 & fibrinogen beta chain & 92 & 3 & AAA52687 & 6.21 & 47.1 & $\mathrm{X}$ & 1.96 & $1 \mathrm{~A}, 2 \mathrm{~A}$ \\
\hline 285 & haptoglobin precursor & 129 & 6 & $\mathrm{NP}$ & 5.08 & 46 & & -2.48 & $1 \mathrm{~B}, 2 \mathrm{~B}$ \\
\hline 292 & haptoglobin- 2 beta chain & 119 & 6 & 005134 & 6.03 & 46.6 & $\mathrm{X}$ & 3.1 & $1 \mathrm{~A}, 2 \mathrm{~A}$ \\
\hline 308 & not identified & & & & 5.37 & 42 & $\mathrm{X}$ & 1.44 & $1 \mathrm{~A}, 2 \mathrm{~B}$ \\
\hline 354 & serum albumin & 119 & 3 & AAA64922 & 5.79 & 22.1 & & 2.36 & $2 \mathrm{C}$ \\
\hline 356 & not identified & & & & 5.74 & 24.2 & $\mathrm{X}$ & -2.17 & $1 \mathrm{~A}, 2 \mathrm{C}$ \\
\hline 364 & haptoglobin-2 alpha & 94 & 5 & 701184A & 5.92 & 18.5 & & -1.78 & $1 \mathrm{~B}, 2 \mathrm{C}$ \\
\hline 373 & $T$-cell receptor type $\mathrm{C}$ alpha region & 79 & 1 & AAB86742 & 5.03 & 15.3 & $\mathrm{X}$ & 3.61 & $1 \mathrm{~A}, 2$ \\
\hline 378 & haptoglobin-1 alpha chain & 100 & 5 & $681073 \mathrm{~A}$ & 5.19 & 16.6 & $\mathrm{X}$ & -1.84 & $1 \mathrm{~A}, 2 \mathrm{C}$ \\
\hline 401 & ATP-citrate (pro-S-)-lyase & 86 & 1 & CAA45614 & 4.78 & 5 & & -1.59 & $1 \mathrm{~B}$ \\
\hline 417 & proapolipoprotein & 250 & 11 & AAA51747 & 5.45 & 26 & & -3.23 & $1 \mathrm{~B}, 2 \mathrm{C}$ \\
\hline 439 & collagen X (subunit 3) & 81 & 3 & CAA42933 & 6.05 & 55.5 & $\mathrm{X}$ & 2.03 & $1 \mathrm{~A}, 2 \mathrm{~A}$ \\
\hline 465 & Ig kappa chain $\mathrm{C}$ region & 78 & 1 & A37927 & 6.45 & 26 & & -2.54 & $1 \mathrm{~B}$ \\
\hline
\end{tabular}

${ }^{a}$ Spot trypsin digests were identified using nano-electrospray mass spectra (nESI-MS/MS), correlated to compiled peptide data (matrixscience). A positive control spot picked from the 2-DE gel molecular weight markers was correctly identified as myoglobin.

the 15 KDa TCR fragment was specific to the recurrent group. The results are shown in Figure 3B. The expression of $24 \mathrm{KDa}$ and $47 \mathrm{KDa}$ TCR fragments is confirmed within both the single event and recurrent populations. However, band densitometry reveals that these higher molecular weight forms predominate in the single inflammatory event group. The recurrent patients display a trend towards higher expression of the $\sim 15 \mathrm{KDa}$ fragment, confirming the initial 2-DE proteomic analysis.

\section{Discussion}

Juvenile idiopathic arthritis (JIA) comprises a heterogeneous group of chronic diseases with highly variable clinical presentations and outcomes. Laboratory testing for pathogenic or prognostic biomarkers within joint fluid and peripheral blood samples is limited. The advent of modern proteomic methodologies, namely 2-dimensional electrophoresis (2-DE) combined with mass-spectrometry (MS), has provided the opportunity to characterize complex protein profiles within synovial fluid or plasma.

The dynamic milieu of synovial fluid is of particular interest as it is composed not only of ultra-filtrated proteins (or cleaved peptides) originating in serum, but also proteins exclusively expressed and secreted by cells localized within the synovial membrane, fluid or cartilage.

The synovial proteome of JIA is likely to be distinct from that found in adult RA. This is because the genetics of JIA are quite different from that of adult disease, the immunology is different, and joint erosion much less common. Furthermore, since children are growing, this may profoundly influence the balance between inflammation and repair mechanisms within the joint.

The ideal biomarker of persistent inflammation in JIA should fulfill a number of criteria, including: detectable levels in early disease, expression which coincides with each inflammatory episode and expression that is restricted to the inflamed joint. We have applied these selection criteria in the current study and have identified a number of putative candidates.

Fibrin(ogen) and haptoglobin precursors, mature active molecules and peptide chain fragments have been positively identified in the current study. Only fibrinogen beta (spot no.
270) and haptoglobin-2 beta (spot no. 292) chains were exclusive to the synovial fluid and overexpressed within the recurrent inflammation patient group. However, since these proteins are not restricted to synovial fluid, have decreased expression levels within recurrent patients, dismisses them as putative biomarkers.

Several proteins have been identified in adult rheumatoid arthritis (RA) and osteoarthritis (OA) patients by conventional 2-DE/MS methodologies, though JIA had to date remained unstudied. Synovial joint-specific biomarkers identified in adults include calgranulins $\mathrm{A}, \mathrm{B}$, and $\mathrm{C},{ }^{12,14}$ fibrinogen $\beta$-chain and fructose bisphosphonate aldolase A and alpha-enolase. ${ }^{15}$ Serum amyloid A (SAA) has been found at increased levels in both plasma and synovial fluid in adult RA patients. A broad range of markers, including C-reactive protein ${ }^{16}$ and haptoglobin, ${ }^{11,14}$ consistent with a chronic inflammatory condition have also been observed.

Additional proteomic studies on progressive joint disease in adults have concentrated on other aspects of the molecular pathology including the presence of autoimmune antigens, ${ }^{17}$ or monitoring of patient response to anti-TNF $\alpha$ therapy. ${ }^{18}$ The authors of a recent, highly relevant study of systemic-onset JIA patients, were able to distinguish responses to an experimental anti-IL-6 receptor therapy. However this study was based on analysis of serum, and of the 23 proteins noted only SAA was discussed. ${ }^{19}$

We have identified the presence of collagen X and T-cell receptor $\alpha \beta$ (TCR) fragments at significantly higher levels within synovial fluids of patients suffering recurrent episodes of inflammation. These may be putative biomarkers of disease persistence.

Collagen X expression was just over 2-fold higher than in the single inflammatory event group. It was found to be limited to the initial inflammatory episode with levels falling in later samples analyzed. Collagen type $\mathrm{X}$ is an extracellular matrix component normally restricted to the interface of articular cartilage and bone. ${ }^{20}$ It is exclusively synthesized by chondrocytes in the growth plate cartilage, though there are conflicting views as to whether a thin 'seam' of permanent collagen $\mathrm{X}$ 
remains in the mature adult. ${ }^{21}$ In the context of recurrent inflammation it is intriguing to find a product of hypertrophic cartilage as a possible biomarker.

Other studies on collagen X postulate that it's deposition correlates with the initiation of calcification in bone formation, ${ }^{22}$ whereas others suggest that collagen X can produce focal inhibition of calcification. ${ }^{23}$ The fragments identified themselves could also play a pathological role in the initiation or development of joint inflammation. The effects of specific type XVIII collagen fragments, for example endostatin, ${ }^{24}$ on the process of angiogenesis are well documented in a number of disease states including arthritis. ${ }^{25}$ Furthermore, increases in collagen I fragments correlate with disease activity scores in adult RA, ${ }^{26}$ whereas collagen II is associated with joint inflammation in juvenile arthritis due to an autoimmune reaction. ${ }^{27}$

However, in our study since the expression of collagen $\mathrm{X}$ is relatively low and is restricted to the initial episodes of inflammation, it may be more indicative of growth, repair, or degenerative change at the bone-cartilage interface.

Further work is required to validate collagen $\mathrm{X}$ as a conclusive biomarker.

Distinct TCR fragment patterns were consistently detected in the synovial fluid of persistently inflamed joints and within other joints in the same patient. This might suggest that inflammation in JIA is mediated by specific T cell clones.

The detection of TCR protein is not unique to JIA but may be detected in a wide range of inflammatory conditions. What may be specific to JIA though, is the oligoclonality of the TCR.

Previous studies have provided evidence of the clonal expansion of specific T-cells which accumulate preferentially in the synovial compartment. ${ }^{28,29}$ The identification of expanded oligoclonal TCRs within and between individual JIA patients has also been previously observed..$^{30}$ The common TCR fragments identified in this study, suggest local (synovial) stimulation by a limited number of antigens. Furthermore, the observation of two identical TCR expression patterns in two distant joints, of an individual, may indicate that cells which enter and proliferate within the inflamed joint are a select subgroup from the peripheral $\mathrm{T}$ cell population.

In a separate study of TCR oligoclonality in a single JIA patient, a converse relationship has also been identified. Here, $\mathrm{T}$ cell clones were actively excluded from the inflamed joint. ${ }^{23,31}$

Our results are in agreement with earlier TCR studies, though we provide data which suggests that the $\mathrm{T}$ cell contribution to inflammation extends beyond early stage disease and could be a requirement for the perpetuation of inflammation. The western blot band densitometry of individual synovial fluids revealed that the lower molecular weight $(\sim 15 \mathrm{KDa}) \mathrm{TCR}$ fragments predominate in the recurrent patient group. Questions remain as to whether the demonstrated TCR fragments are functionally active or whether they are a product of constitutive degradation or recycling.

This is the first study to characterize the synovial proteome from patients with JIA. It has revealed a small subset of biomarkers which may play a specific role in determining the pathophysiological state within the chronically inflamed joint.

It is unfortunate that a number of spots with the most dramatic changes $(33,241,245$, and 356) had unsufficient protein yields within gel digests to be definitively identified. The protein loading and sensitivity of the 2-DE technique will be improved in future studies by progressing to larger format, higher capacity gels with fluorescent Cy dye labeling of samples.
Further studies will be necessary to evaluate the clinical significance of these putative biomarkers.

It could be argued that a study comparing the subgroups of JIA, i.e., Oligo vs Poly might have been more appropriate. Our hypothesis was that, irrespective of JIA subtype, markers of disease persistence may exist that are common to all subgroups. This pilot study was looking for change that could be measured over time. Thus, the recurrence of joint inflammation was a useful event that could be tracked over time and correlated to findings at outset.

Having demonstrated that it is possible to identify the JIA proteome, we wish to validate our findings in a further cohort of patients with newly diagnosed JIA in order to compare the synovial proteome with in JIA subsets and to verify whether the markers we have identified do truly predict disease progression.

Abbreviations. JIA, juvenile idiopathic arthritis; TCR, T cell receptor; RA, rheumatoid arthritis; SF, synovial fluid; OA, osteoarthritis; RK, right knee; ESI-MS, electrospray ionizationmass spectrometry; MWt, molecular weight; ESR, erytrocyte sedimentation rate; CRP, C-reactive protein; RF, Rheumatoid Factor.

Acknowledgment. The authors would like to thank the Research and Development Office, Health and Personal Social Services, Northern Ireland for financial support of this study.

\section{References}

(1) Minden, K.; Niewerth, M.; Listing, J.; Biedermann, T.; Bollow, M.; Schontube, M.; Zink, A. Arthritis Rheum. 2002, 46 (9), 2392.

(2) Oen, K.; Malleson, P. N.; Cabral, D. A.; Rosenberg, A. M.; Petty, R. E.; Cheang, M. J. Rheumatol. 2002, 29 (9), 1989.

(3) Ravelli, A. Clin. Exp. Rheumatol. 2004, 22 (3), 271.

(4) Petty, R. E.; Southwood, T. R.; Baum, J.; Bhettay, E.; Glass, D. N.; Manners, P.; Maldonado-Cocco, J.; Suarez-Almazor, M.; OrozcoAlcala, J.; Prieur, A. M. J. Rheumatol. 1998, 25 (10), 1991-4

(5) Flato, B.; Lien, G.; Smerdel, A.; Vinje, O.; Dale, K.; Johnston, V.; Sorskaar, D.; Moum, T.; Ploski, R.; Forre, O. J. Rheumatol. 2003, 30 (2), 386.

(6) Foster, H. E.; Marshall, N.; Myers, A.; Dunkley, P.; Griffiths, I. D. Arthritis Rheum. 2003, 48 (3), 767.

(7) Fantini, F.; Gerloni, V.; Gattinara, M.; Cimaz, R.; Arnoldi, C.; Lupi, E. J. Rheumatol. 2003, 30 (3), 579.

(8) Lindqvist, E.; Eberhardt, K.; Bendtzen, K.; Heinegard, D.; Saxne, T. Ann. Rheum. Dis. 2005, 64 (2), 196.

(9) Oen, K.; Reed, M.; Malleson, P. N.; Cabral, D. A.; Petty, R. E.; Rosenberg, A. M.; Cheang, M. J. Rheumatol. 2003, 30 (4), 832.

(10) Oen, K.; Malleson, P. N.; Cabral, D. A.; Rosenberg, A. M.; Petty, R. E.; Reed, M.; Schroeder, M. L.; Cheang, M. J. Rheumatol. 2003, 30 (3), 585.

(11) Kantor, A. B.; Wang, W.; Lin, H.; Govindarajan, H.; Anderle, M.; Perrone, A.; Becker, C. Clin. Immunol. 2004, 111 (2), 186.

(12) Liao, H.; Wu, J.; Kuhn, E.; Chin, W.; Chang, B.; Jones, M. D.; O’Neil, S.; Clauser, K. R.; Karl, J.; Hasler, F.; Roubenoff, R.; Zolg, W.; Guild, B. C. Arthritis Rheum. 2004, 50 (12), 3792.

(13) Pappin, D. J.; Hojrup, P.; Bleasby, A. J. Curr. Biol. 1993, 3 (6), $327-32$.

(14) Sinz, A.; Bantscheff, M.; Mikkat, S.; Ringel, B.; Drynda, S.; Kekow, J.; Thiesen, H. J.; Glocker, M. O. Electrophoresis 2002, 23 (19), 3445 .

(15) Tilleman, K.; Van Beneden, K.; Dhondt, A.; Hoffman, I.; De Keyser, F.; Veys, E.; Elewaut, D.; Deforce, D. Proteomics 2005, 5 (8), 2247.

(16) Kuhn, E.; Wu, J.; Karl, J.; Liao, H.; Zolg, W.; Guild, B. Proteomics 2004, 4 (4), 1175

(17) Xiang, Y.; Sekine, T.; Nakamura, H.; Imajoh-Ohmi, S.; Fukuda, H.; Nishioka, K.; Kato, T. Arthritis Rheum. 2004, 50 (5), 1511.

(18) Drynda, S.; Ringel, B.; Kekow, M.; Kuhne, C.; Drynda, A.; Glocker, M. O.; Thiesen, H. J.; Kekow, J. Pathol. Res. Practice 2004, 200 (2), 165.

(19) Miyamae, T.; Malehorn, D. E.; Lemster, B.; Mori, M.; Imagawa, T.; Yokota, S.; Bigbee, W. L.; Welsh, M.; Klarskov, K.; Nishomoto, N.; Vallejo, A. N.; Hirsch, R. Arthritis Res. Ther. 2005, 7 (4), R746755 . 
(20) Eyre, D. Arthritis Res. 2002, 4 (1), 30-35.

(21) Bahrami, S.; Plate, U.; Dreier, R.; DuChesne, A.; Willital, G. H.; Bruckner, P. Matrix Biol. 2001, 19 (8), 707.

(22) Shen, G. Orthod Craniofac. Res. 2005, 8 (1), 11.

(23) Babarina, A. V.; Mollers, U.; Bittner, K.; Vischer, P.; Bruckner, P. Matrix Biol. 2001, 20 (3), 205.

(24) O'Reilly, M. S.; Boehm, T.; Shing, Y.; Fukai, N.; Vasios, G.; Lane, W. S.; Flynn, E.; Birkhead, J. R.; Olsen, B. R.; Folkman, J. Cell 1997, 88 (2), 277.

(25) Nagashima, M.; Asano, G.; Yoshino, S. J. Rheumatol. 2000, 27 (10), 2339.

(26) Kotaniemi, A.; Risteli, J.; Aho, K.; Hakala, M. Clin. Exp. Rheumatol. 2003, 21 (1), 95.

(27) Myers, L. K.; Higgins, G. C.; Finkel, T. H.; Reed, A. M.; Thompson, J. W.; Walton, R. C.; Hendrickson, J.; Kerr, N. C.; Pandya-Lipman,
R. K.; Shlopov, B. V.; Stastny, P.; Postlethwaite, A. E.; Kang, A. H. Arthritis Rheum. 2001, 44 (8), 1775.

(28) Grom, A. A.; Thompson, S. D.; Luyrink, L.; Passo, M.; Choi, E.; Glass, D. N. Proc. Natl. Acad. Sci., U.S.A. 1993, 90 (23), 11104.

(29) Thompson, S. D.; Grom, A. A.; Bailey, S.; Luyrink, L.; Giannini, E. H.; Murray, K.; Passo, M. H.; Lovell, D. J.; Choi, E.; Glass, D. N. J. Rheumatol. 1995, 22 (7), 1356.

(30) Thompson, S. D.; Murray, K. J.; Grom, A. A.; Passo, M. H.; Choi, E.; Glass, D. N. Arthritis Rheum. 1998, 41 (3), 482.

(31) Wedderburn, L. R.; Maini, M. K.; Patel, A.; Beverley, P. C.; Woo, P. Int. Immunol. 1999, 11 (4), 535.

PR060129T 